\title{
The Study of Dual-Tutored System in the Process of Cultivation on Full-time Professional Degree Graduates Based on Integration of Production and Education
}

\author{
Jian-guo HUANG ${ }^{1, *}$, Xiao-xi $\mathrm{LI}^{2}$ and Yao-hui $\mathrm{CHEN}^{2}$ \\ ${ }^{1}$ Graduate School, Nanjing University of Finance and Economics, Nanjing, Jiangsu, China \\ ${ }^{2}$ School of Economics, Nanjing University of Finance and Economics, Nanjing, Jiangsu, China \\ ${ }^{*}$ Corresponding author
}

\begin{abstract}
Keywords: Integration of Production and Education; Full-time Professional Degree; Dual-tutored System.
\end{abstract}

\begin{abstract}
The dual-tutored system is a dual-tutoring working mechanism for full-time professional degree graduates in order to make up for the lack of practical experience of postgraduates and implement the integration of production and education. The "dual-tutored" system is a brand-new cultivation method in the process of full-time professional graduates. There are still a number of problems in the process of practice. How to improve this system? This paper proposes to give full play to the leading role of government departments and the main role of colleges and universities in the process of personnel training, establish a participation mechanism for the whole process of outside tutor training, implement dual-tutored assessment and incentive mechanisms, and improve mentoring and appraisal system for professional graduates tutors, strengthen the communication and exchange between the tutors outside schools, graduate students, and the tutors inside schools.
\end{abstract}

\section{Full-time Professional Degree Graduates and Double-Tutored System}

To actively develop professional degree education with Chinese characteristics, since 2009, the Ministry of Education has expanded the scope of enrolling full-time master degree majoring in fresh graduates, and decided to increase the enrollment scale of full-time professional degree graduates, mainly for recruiting fresh graduates. In 2009, the Ministry of Education issued Several Opinions on the Training of Full-time Professional Degree Graduates (Teaching and Research [2009] No. 1) to make it clear that, "The goal of a professional graduate student is to develop high-level application-oriented specialized talents who master a professional (or occupation) basic theory and broad professional knowledge, have strong abilities to solve practical problems, be able to undertake professional or technical management work, and have good professional qualities", as well required that colleges and universities should pay attention to absorb and use social resources, cooperate to establish joint training grounds, jointly train professional graduates, reform innovative and practical teaching mode. In 2013, the Ministry of Education as well the Ministry of Human Resources and Social Security issued Opinions on Further Promoting the Reform of Professional Graduates Training Model (Teaching Research [2013] No. 3), stated that, "Professional degree graduate education should vigorously promote the dual tutorial system inside and outside schools. Focus on instructors' guidance inside schools and pay attention to instructors' role outside the school. Based on the characteristics of different professional degree categories, we will explore the tutor group system and establish a team of mentors composed of experts in the relevant disciplines and professional (industry) experts to jointly guide graduate students."

\section{Literature Review on Dual-Tutored System of Full-time Professional Degree}

\subsection{Research on the connotation of dual-tutored system}

Lu Hongjuan et al. (2013) believed that the double-tutored system referred to a teaching and management system with a combination of a tutor inside the school with rich professional experience and a tutor outside the school with great practical experience. Jiang Degang and Yang 
Daoyu (2013) proposed that the dual tutored-system meant that the school tutors had rich theoretical knowledge and professional knowledge. The tutors outside the school have abundant practical skills. Two tutors could guide a graduate student at the same time. In the process of exchange and cooperation, two tutors would exchange and cooperate with each other on the practical problems encountered in the cultivation of professional degree graduates, so that they could develop graduate students appropriately. Zheng Wenxuan et al. (2015) believed that dual tutors were not limited to two tutors, but might also be social workers in other colleges, enterprises, research institutes, etc. They are committed to the cultivation of high-level applied talents.

\subsection{Research on the existing problems on the implementation of the dual-tutored system}

Lu Hongjuan (2013) held that there were some problems in the implementation of the dual-tutored system. For example, the implementation of the "double-tutored system" lacks institutional guarantees from the government and schools; and secondly, there is no perfect system of regulations on outside tutors. It will make them lack enthusiasm, the role of outside tutors cannot be fully played, the number of practical bases for professional degree graduates is not enough, schools and enterprises lack deep cooperation. Chen Wenxing, Ma Bin et al. (2013) argued that there were problems in the course of the operation of the double-tutoring system in which the tutors' duties were unclear, the tutor management was not in place, and the dual tutor system was implemented in the form. Zheng Wenxuan et al. (2015) also supported that, in the process of implementation of the "double-tutored system", schools paid insufficient attention to the tutors outside the school, and the management measures needed to be strengthened.

\subsection{Different countermeasures and suggestions for the implementation of the dual-tutored system}

Xin Deshu and Xiong Wei (2012) believed that it was necessary to improve the dual-tutored system by developing joint training of schools and enterprises and institutions, and establishing and improving the management and assessment system for professional graduate student tutors. Wang Hui and Zhao Guohong (2015) believed that schools should strengthen the emphasis on the dual-tutored system, actively improve various funding guarantee systems, arouse the enthusiasm of the external tutors, and establish a scientific and reasonable dual-supervisor selection system to ensure the effectiveness of the dual-tutored system; Su Jianbing and Liang Wei et al. (2015) thought that it was necessary to clarify the job responsibilities of the tutors inside and outside the school, and strictly select outside tutors and increase the training and learning guidance for inside tutors to promote the implementation of the dual-tutored system.

On the basis of the above scholars' discussion, "dual tutor" refers to the tutors inside and outside the school, or the theoretical tutors and practical tutors. Of course, in the implementation process, it is not only limited to the restriction of the number, but also can be expanded to tutor guidance team based on the requirement. Since the implementation of the "double-tutored system" for full-time professional degree, many colleges and universities have not implemented it, only some colleges and universities have begun effective exploration in some majors, but there are still some problems in the implementation process, including the problems on schools, enterprises, tutors, and students themselves, as well the problems on funding and management system issues. To ensure the smooth implementation of the "double-tutored system" for full-time professional graduate degree education, we should continue to improve system design, operative mechanism and some other aspects.

\section{Current Major Problems in the Practice of the Dual-Tutored System of Full-time Professional Degree}

The dual-tutored system is an innovative model for deepening the integration of production and education, advancing the collaboration between universities and enterprises to cultivate full-time professional degree graduates, and is also an important guarantee for improving the quality of full-time professional degree graduates. Outside mentors with rich practical experience or occupational experience should be recruited to participate in the whole process of cultivating 
postgraduates of professional degrees, which can make up for the inadequacy of the university's practical ability in personnel training, give full play to their respective advantages, and develop high-level applied talents according with the requirement of economic and social development. However, in the practical process of cultivating full-time professional graduate students, there are still many problems in the dual-tutored system, which restrict the advantages of the dual-tutored system to be fully utilized.

\subsection{The leading role of government departments is not enough}

The implementation of the dual-tutored system for full-time professional degrees requires the deep integration of schools and enterprises, and the development of all-round cooperation. The government has not established a unified education and industry integration development pattern, unable to play the important major role of universities and enterprises, and cannot promote the integration of production and education personnel training reform, and the bidirectional connection of supply and demand on production and education has not been further promoted. There is a lack of policy support system in implementing the integration project of production, learning and research, the implementation of the fiscal and tax land policy and the strengthening of financial support. It does not actively promote the school-enterprise cooperation and the implementation of dual-tutored system for full-time professional degree.

\subsection{The main role of personnel training in colleges and universities does not play enough}

With the implementation of a series of national major strategies such as the "Innovation-Driven Development Strategy", "One Belt and One Road", and "Made in China 2025", national and economic and social development urgently require high-level applied talents, and professional degree graduate education is an important aspect for high-level applied talents. However, most colleges and universities do not pay enough attention to the training of professional degree graduates, and they do not fully understand the important role of dual tutors in the cultivation of professional graduates. The phenomenon of "academic" cultivation of professional graduates still exists in higher vocational colleges.

\subsection{The working mechanism of dual-tutored system is not fully implemented}

In the actual cultivation of professional degree graduates, the enthusiasm of outside tutors is not high. Some of them just leave their names and do not really participate in all steps of the training of professional graduates, and even provide insufficient guidance in the practical step. In addition, the duties of both the school tutor and the outside tutor are unclear, and they are lack of connection and communication each other, so it is impossible to learn from each other and complement each other, which seriously affects the effectiveness of the tutoring.

\section{The Suggestion for Perfecting the Dual-Tutored System for Full-time Professional Degrees under the Concept of Integration of Production and Teaching}

\subsection{Governments should play their leading role in promoting the integration of production and teaching between universities and enterprises}

President $\mathrm{Xi}$ has already put forward the requirements in strengthening the integration of production, education and research in the report of the 19th National Congress of the Communist Party of China. In the deployment of "priority development of education", President Xi proposed that we should deepen the integration of production and education, at the same time, promote the cooperation between school and enterprise. In order to implement the spirit of the 19th Party Congress, the General Office of the State Council issued the document of Several Opinions of Deepening the Integration of Production and Teaching on the 19th December last year. The document emphasized we must give full play to the coordination of supply and demand, including the overall planning of government, the key subject of enterprises, the mainstream of personnel training reform and social organizations. We should also promote the reform of personnel training under the framework of the integration of production and teaching, strengthen the construction of 
faculties of the integration of production and teaching, improve the classification and training system for academic talents and applied talents in higher education, improve the proportion of applied talents, support the personnel of enterprise to teach in schools, and the last, encourage exploring the position program for industrial teachers. At present, colleges are directly responsible for the training of graduates of professional degrees, while the industries and enterprises have no direct responsibilities and obligations. However, the goal of training high-level applied talents for education of postgraduate in professional degrees must be realized through the form of cooperation between school and enterprises. This requires the government to give full play to its leading role to promote the cooperation between industry, universities and research institutes, and promote the joint training of enterprises and universities for professional graduates from the top-level design, policy support, funding etc. For example, the government of Jiangsu Province has vigorously promoted the workstations of enterprise-graduated students since 2009, and supported those enterprises which set up the workstations in terms of policies and funds. The government has also established the cooperation platforms for production, education and research, and the collaborative training platforms of graduates for universities and enterprises. At the same time, the enterprise workstation of graduates has become an effective carrier for the construction and implementation of the dual-tutored system. In addition, the government of Jiangsu Province has pioneered the selection of industrial professors nationwide since 2009, which was jointly implemented by the Provincial Talents Office, the Provincial Department of Education, the Provincial Department of Science and Technology, the Provincial Human Resources and Social Security, and the Provincial Department of Finance. The industrial professors that selected from industries and enterprises should participate in the formulation or revision of training programs of graduates in universities. They shall be guided or jointly supervised the graduate to undertake the construction and teaching of graduates' practical courses. This also provides strong support for the "dual-tutored system" that cultivating the full-time professional graduates.

\subsection{Colleges should give play to the main role of cultivating graduates and promote the smooth implementation of the dual-tutored system}

As the key position for training graduates, colleges should fully realize the importance of training the full-time professional graduates, and profoundly understand the significance of the "dual-tutored" system for cultivating professional graduates. Only in this way can colleges and universities give full play to the main role. Colleges should give full play to carry out the all-round cooperation and exchanges between universities and enterprises, and strive to achieve complementary advantages, especially making up the shortcomings of practical teaching in colleges; highlighting the characteristics of professional and practical in professional degrees; building a bridge between universities and companies, university tutors and corporate tutors, tutors and graduates; and creating a great atmosphere for personnel training, thus promoting the implementation of the working mechanism of "dual-tutored" for full-time professional graduates. At the same time, colleges should also provide the powerful policy guarantees in terms of selecting, funding and other aspects for tutors outside the colleges. For example, professional experts in the field of industry are selected as external tutors for full-time graduate students, and certificates are issued. Off-campus tutors are also provided to ensure that tutors outside the school effectively participate in the graduate training process. Such as employing the experts in selected fields as the industrial tutors for full-time professional graduates while issuing them certificates; setting up the special fund for the industrial tutors to ensure them participating in the cultivating process of graduates effectively.

\subsection{Promoting the academic tutors and industrial tutors to participate in the whole process of cultivating postgraduates and fully implementing the dual-tutored system}

The process of the development of professional training program, graduate's individual training program, course teaching, thesis guiding and internship training should be cooperated by the academic tutors and industrial tutors. First of all, the academic tutors and industrial tutors must work together to demonstrate and formulate the training program. The theory and practice should 
both be counted into consideration when formulate the curriculum, also, the applicability and the training of students' ability of practice should be highlighted in the whole process. Secondly, colleges must set up the courses such as the enterprise-based courses and case-based courses, and encourage the academic tutors and industrial tutors to work closely to undertake the teaching of these practical courses. Thirdly, the academic tutors and industrial tutors need to jointly participate in the process of thesis proposal, mid-term assessment, and thesis defense of professional graduates, and check repeatedly to ensure the applicability and professionality of student's thesis. In addition, the industrial tutors should give full play to their role of and bridges - promoting the cooperation between enterprises and colleges in the process of project cooperation, such as the establishment of practice base which could provide a platform of employment for graduates of professional degrees.

\subsection{Strengthening the communication between academic tutors and industrial tutors, striving to improve the dual-tutored system}

To improve the "dual-tutored" system and give full play to the role of dual tutors, the all-rounded communication must be strengthened. The "dual-tutored" system is based on the guidance of the academic tutors, supplemented by guidance from industrial tutors, and colleges should establish the communication mechanisms between the academic tutors and industrial tutors. Through regular or irregular communication between the two tutors, it can not only exert the role of strong foundational theory of the academic tutors, but also can give full play to industrial tutor's role of practical problem-solving ability. Only in this way, will there be a phenomenon of disconnection between basic theoretical teaching and practical skills training in the process of professional postgraduate training. For the communication between the industrial tutors and students, the student enters into the company that the industrial tutor works in to as an internship. The industrial tutor also comes to the college to participate in classroom lectures, academic lectures, dissertation defenses, etc. to strengthen his or her academic exchanges. Meanwhile, tutors and students can solve the problems encountered in the process of learning and practice via calls, emails, interviews, and other forms.

\subsection{Strengthening the management of selecting and building a guarantee system of dual- tutored system}

Clarifying the duties of industrial tutors and academic tutors and establishing an operating mechanism of "dual-tutored". Colleges should formulate the methods of selecting and managing tutors for the off-campus professions. The selection and employment of industrial tutors can be measured not only by their professional titles and scientific research results, but also should focus on industrial experience, practical experience, and the ability of practical guidance. On the other side, the selection and appointment of the academic tutors should not only pay attention to their academic level and guiding ability, but also take their practical experience and the problem-solving ability into consideration. Colleges should actually employ some outstanding teachers who both have high academic levels and rich practical experiences to serve as tutors. The college should form a "dual-tutored" guidance system which integrated the enterprises and college by implementing the jointed tutors and the equipment of graduates. The college shall also strengthen the performance assessment of the industrial tutors and academic tutors, and establish a management system with clear responsibilities, to ensure the effectiveness of the "dual-tutored" system.

\section{Acknowledgements}

Authors are grateful to the Brand Major Construction Project of University in Jiangsu (PPZY2015B103); Teaching Reform Project of Jiangsu (2017JSJG047); Project of Evaluation Committee of Higher Education Society in Jiangsu (Pgwyh07101); Teaching Reform Project of Nanjing University of Finance and Economics (JGZ1805).

\section{References}

[1] Z.Y., Du. Exploring the Innovation, Deepening the Reform and Promoting the Professional 
Degree Students to a New Level. Academic Degree and Graduate Education, Vol. (1), 2016, pp. $1-6$.

[2] B.Y., Huang. A New Era of the Educational Development of Professional Degree Graduate in China. Academic Degree and Graduate Education, Vol. (10), 2010, pp. 1-5.

[3] Y. Wang, Z.C., Dong, L. Zhou. The Exploration and Practice of Construction of the Dual-tutored System for Full-time Professional Degree Graduates: A Case Study of Hohai University. Journal of Graduate Education, Vol. (6), 2015, pp. 75-79.

[4] G. Zhen, The Construction of Tutor Team for Full-time Professional Degree Graduates: A Case Study of Yangzhou University. Academic Degree and Graduate Education, Vol. (11), 2014, pp. 10-14.

[5] H.J., Lu. Full-time Financial Professional Dual-tutored System. Vocational Education, 2013 (4).

[6] D.G., Jiang, D.Y., Yang, Z.Q., Dai. On the Dual-tutored System for Medical Graduates. Researches in Medical Education, Vol. (11), 2014, pp. 10-14.

[7] W.X., Zhen, Y. Yang et al. An Analysis of Training Model of the Dual-tutored System for Full-time Professional Graduates. Vol. (8), 2015.

[8] W.X., Chen, B. Ma et al. Construction countermeasures for Dual-tutored System of Full-time Professional Graduates. Journal of Dalian Nationalities University, Vol. (9), 2013.

[9] H.Wang, G.H., Zhao. The Implementation and Countermeasures of the Dual-tutored system for Full-time Degree Graduates of Landscape Architecture. Higher Agricultural Education, Vol. (4), 2015, pp. 93-96.

[10] D.S., Xin, X.W. et al. Thoughts on the Dual-tutored System of Professional Degrees. Higher Agricultural Education, Vol. (6), 2012.

[11] Y.D., Zhang and Z.H., Lu, Y.L., Wang, Research on the 'Dual Mechanism' of Cultivating Professional Degree of Graduates--Taking the Practice of the Specialized Project of Huaiyin Institute of Technology as an Example. Academic Degrees \& Graduate Education, 2014 (3): 14-17.

[12] Z.Z., Huang, The Perfection and Popularization of the 'Dual-Tutored System' in the Teaching and Training of the Master of Law. University Education, Vol.2. 2012, pp. 27-30.

[13] J.B., Su and J., Liang, Y., Shu. Research on the Effective Operation Function of the 'Dual-Tutored' System for Professional Degree Graduates. University Education, 2015 (1): 13-15.

[14] E.L., Cao and L.C., Zhang. Research on the 'Dual-Tutored' System of Full-time Professional Graduate Education. Education Exploration, 2015 (8).

[15] D.D., Xu and D.Y., Yang, Y.M., Li, S.X., Li. Exploration and Practice of Out-school Tutor Work Mechanism for Social Sciences Professional Graduates---Taking Assets Assessment Specialty of Beijing Technology and Business University as an Example [J]. Academic Degrees\& Graduate Education, Vol. (4), 2017: pp. 31-34.

[16] Y., Qi, Research on 'Dual-Tutored' System for Professional Degree Graduate Education, Guangxi Normal University, 2014.

[17] Ministry of Education of the People's Republic of China. Several Suggestions on Training Postgraduates for Full-time Master Degrees. Education \&Research, Vol. (1) 2009.

[18] Ministry of Education of the People's Republic of China. Suggestions on Deepening the Reform of Training Models for Professional Graduate Students. Education \&Research, Vol. (3) 2013.

[19] General Office of the State Council of the People's Republic of China. Some Suggestions on Deepening the Integration of Production and Education. State Council, Vol. (95), 2017. 